\title{
Bony Hemangioma of Maxillary Sinus-A Rare Presentation
}

\author{
${ }^{1}$ Shashidhar S Suligavi, ${ }^{2} \mathrm{MK}$ Darade, ${ }^{3}$ Chandrashekharayya SH, ${ }^{4} \mathrm{SS}$ Chougule
}

${ }^{1}$ Assistant Professor, Department of ENT and Head and Neck Surgery, S Nijalingappa Medical College and HSK Hospital and RC Bagalkot, Karnataka-587102, India

${ }^{2}$ Professor and Head, Department of ENT and Head and Neck Surgery, S Nijalingappa Medical College and HSK Hospital and RC Bagalkot, Karnataka-587102, India

${ }^{3,4}$ Assistant Professor, Department of ENT and Head and Neck Surgery, S Nijalingappa Medical College and HSK Hospital and RC Bagalkot, Karnataka-587102, India

Correspondence: Shashidhar S Suligavi, Assistant Professor, Department of ENT and Head and Neck Surgery, S Nijalingappa Medical College and HSK Hospital and RC Bagalkot, Karnataka-587102, India, Mob: 09448964141 e-mail: ssshashidhar@yahoo.co.in

\section{Abstract}

Hemangioma of maxillary sinus is a rare entity. We present a case with an inconclusive preoperative diagnosis which was treated by excision of entire tumor by medial maxillectomy through lateral rhinotomy approach. There is no recurrence after two years. The literature on the topic is reviewed.

Keywords: Hemangioma, maxillary sinus, medial maxillectomy.

\section{INTRODUCTION}

Even though hemangiomas of head and neck are common, those of nasal cavity and paranasal sinuses are rare. ${ }^{1,2}$ Incidence of hemangioma of maxillary sinus is still rarer compared to nasal cavity. In a study of 359 cases of neoplasms of nose and paranasal sinuses of which 14 cases were hemangiomas and none were from maxillary sinus. ${ }^{3}$ Dahlin DC reviewed 3947 cases of bone tumor in which only 3 cases were from maxillary bone. ${ }^{4}$ Still hemangiomas of maxillary sinus needs to be considered because of its inconclusive preoperative diagnosis and profuse bleeding during biopsy or surgery.

We report a case of hemangiomas of maxillary sinus which showed an aggressive behavior with an inconclusive preoperative diagnosis of malignancy.

\section{CASE REPORT}

A 32-year-old female presented to us with history of recurrent epistaxis, left nasal block and left proptosis since three months. Her past history was unremarkable. Anterior rhinoscopy showed a polypoidal mass with necrosis filling whole of the left nasal cavity pushing the septum to right. There were no other abnormalities in nasopharynx, throat and ear. CT scan with contrast showed a mass filling left nasal cavity, left maxillary sinus with destruction of its medial wall and lamina papyracea and floor of the orbit (Fig. 1). Preoperative biopsy was done under local anesthesia and histopathological report was inconclusive. The tumor was completely excised with medial maxillectomy through lateral rhinotomy approach and was associated with minimal bleeding. Postoperative period was uneventful.

The mass measured $4.5 \times 5 \times 6 \mathrm{~cm}$ (Fig. 2). Microscopy showed blood filled spaces separated by bony trabeculae and proliferative blood vessels of different sizes lined by endothelium (Fig. 3). Proptosis subsided gradually and patient showed no recurrence after two years of follow-up.

\section{DISCUSSION}

Hemangiomas are benign vascular lesions.More than half of them are located in head and neck region but are rarely seen in nose and paranasal sinuses.

Most frequent symptoms are nasal obstruction and recurrent epistaxis. Bony (invasive) hemangiomas originating from nasal bones, maxilla and angiosarcomas should be differentiated from mucosal (benign) hemangiomas from mucosa, since their clinical behavior and treatment are different. ${ }^{5,6}$ In our case mass was invasive and bled minimally during surgery. However CT or MRI are 


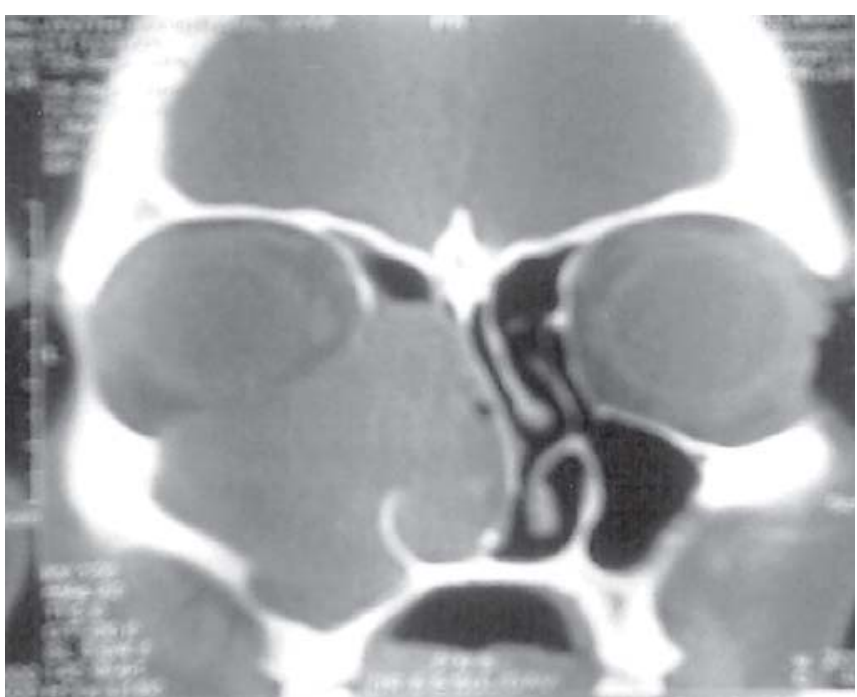

Figure 1: CT scan showing mass in left maxillary sinus, invasion of lamina papyracea

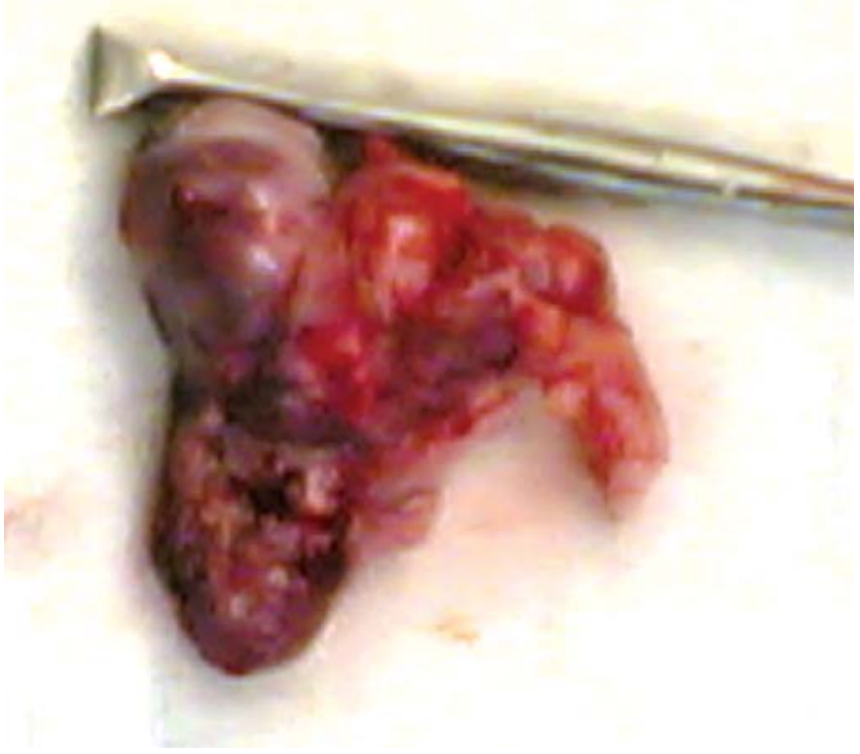

Figure 2: Excised hemangioma mass

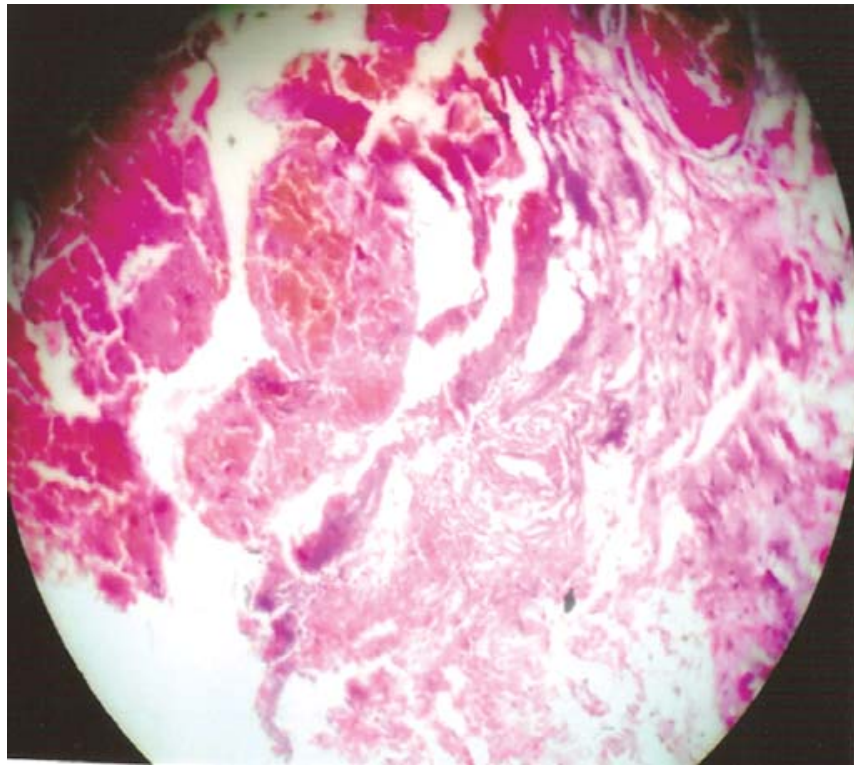

Figure 3: Microscopic picture showing blood filled spaces separated by bony trabeculae and proliferative blood vessels of different sizes lined by endothelium

frequently of limited help in the preoperative diagnosis but are clearly useful in detecting vascularity, bone destruction and selecting surgical approach depending on extent. An unrestricted field of view is advisible during surgery for complete excision and to control the hemorrhage and blood transfusion should also be planned in advance.

\section{REFERENCES}

1. Batsakis JG, Rice DH. The pathology of head and neck tumours: Vasoformative tumours. 9A Head and Neck Surgery 1981a;3:23139.

2. Batsakis JG, Rice DH. The pathology of head and neck tumours: Vasoformative tumours. 9B Head and Neck Surgery 1981b;3:32639.

3. Eggston AA, Wolff, D. Histopathology of ear, nose and throat, Williams and Wilkins, Baltimore 1947;816.

4. Dahlin DC. Bone Tumours, C. Thomson, Springfield, Illinois 1979;100.

5. Ghish LM, Samanta A, Nandy T, Das S. Hemangiomas of the maxilla. Journal of Laryngology and Otology 1988;102:725-26.

6. Kaplan HY, Kessler A, Feibel D, Tsur H. Nasal bone hemangioma. Journal of Laryngology and Otology 1991;105:38991. 